\title{
Karyomorphology and karyotype asymmetry in the South American Caesalpinia species (Leguminosae and Caesalpinioideae)
}

\author{
P.S. Rodrigues, M.M. Souza and R.X. Corrêa \\ Centro de Biotecnologia e Genética, Departamento de Ciências Biológicas, \\ Universidade Estadual de Santa Cruz, Ilhéus, BA, Brasil \\ Corresponding author: R.X. Corrêa \\ E-mail: ronanxc@uesc.br
}

Genet. Mol. Res. 13 (4): 8278-8293 (2014)

Received May 7, 2013

Accepted June 10, 2014

Published October 20, 2014

DOI http://dx.doi.org/10.4238/2014.October.20.4

\begin{abstract}
With the purpose of addressing the pattern of karyotype evolution in Caesalpinia species, chromosome morphology was characterized in five species from Brazil, and karyotypic asymmetry was analyzed in 14 species from South America. All accessions had the chromosome number $2 \mathrm{n}=24$, which was first described here for Caesalpinia laxiflora Tul. and Cenostigma macrophyllum Tul. The karyotype formula of C. laxiflora, Caesalpinia pyramidalis Tul., and $C$. macrophyllum was $12 \mathrm{~m}$. The formula varies amongst the populations of Caesalpinia bracteosa Tul. $(11 \mathrm{~m}+1 \mathrm{sm})$ and Caesalpinia echinata Lam. $(10 \mathrm{~m}+2 \mathrm{sm}$ and $9 \mathrm{~m}+3 \mathrm{sm})$. The intra- and interspecific variations in chromosome length were significant (analysis of variance, $\mathrm{P}<0.05)$. Analyzing the asymmetry index $(\mathrm{AI})$, revealed that Caesalpinia calycina Benth. had the most asymmetrical karyotype $(\mathrm{AI}=10.52)$, whereas Caesalpinia paraguarienses $(\mathrm{D}$. Parodi) Burkat. and Caesalpinia gilliesii (Hook.) Benth. had the most symmetrical karyotypes ( $\mathrm{AI}=0.91$ and 1.10 , respectively). There has been a trend to lower AI values for the Caesalpinia s.l. species assigned in Libidibia and intermediate values for those combined into Poincianella. On the
\end{abstract}


other hand, the karyotypes of Erythrostemon species had extremely different AI values. This study confirms the existence of karyotype variability in Caesalpinia s.l. while revealing a possible uniformity of this trait in some of the new genera that are being divided from Caesalpinia s.1. More broadly, the $2 \mathrm{n}=24$ chromosome number is conserved. Metacentric chromosomes and low AI values predominate among Caesalpinia s.l. and Cenostigma.

Key words: Brazilwood; Caesalpinieae; Cytogenetics; Evolution

\section{INTRODUCTION}

Caesalpinia L. (Leguminosae - Caesalpinioideae - Caesalpinieae), analyzed as Caesalpinia L. s.l., comprises approximately 140 species with morphological characteristics that are very similar to each other (Lewis, 1998; Gasson et al., 2009). Caesalpinioideae has great interspecific and intraspecific variability in the number of chromosomes, and many species have diploid or an unknown chromosome number (Beltrão and Guerra, 1990; Jena et al., 2004; Biondo et al., 2005, Rodrigues et al., 2012). Taxonomic studies support the hypothesis that Caesalpinioideae is a non-natural group comprising paraphyletic tribes (Tucker and Douglas, 1994; Käss and Wink, 1996; Doyle et al., 1997, 2000; Herendeen, 2000; Bruneau et al., 2001; Kajita et al., 2001). Thus, phylogenetic analysis with molecular markers aided in the understanding of this subfamily (Haston et al., 2005; Bruneau et al., 2001, 2008).

Cytogenetic studies are important to Caesalpinioideae studies, but they are still scarce in this subfamily (Biondo et al., 2005). Cytogenetic analysis has been used in cytotaxonomic analyses, particularly by comparing the number and morphology of chromosomes of species at different taxonomic levels. Variations in the number and position of satellites in karyotypes allow inferences about the relationship between karyotype evolution and related taxa.

In the Caatinga biome of Brazil, Caesalpinieae is represented by nine genera, four of which belongs to Caesalpinia clade: Cenostigma Tul., Erythrostemon Cav., Libidibia (DC.) Schltdl., and Poincianella Britton \& Rose, with these last three genera segregated from Caesalpinia s.1. (Gasson et al., 2009; Queiroz, 2009, 2010; Warwick and Lewis, 2009; Manzanilla and Bruneau, 2012). The Caesalpinia s.l. species that are reported to be native to Brazil occur in natural populations from Bahia and other states in northeastern Brazil, mainly in semiarid region. Most of these species belong to the Poincianella, Erythrostemon and Libidibia genera (Lewis, 1998; Queiroz, 2009, 2010). Only five Brazilian Caesalpinia s.l. species have their karyomorphological data published (Rodrigues et al., 2012). Of the Caesalpinia s.l. species that are native to other countries, only three species have been thoroughly examined in terms of karyomorphology (Cangiano and Bernardello, 2005). The literature reporting a higher number of Caesalpinia s.l. species only refers to the chromosome number $2 n=24$, the identification of some polyploid populations, and partial karyomorphological variations.

Species of great economic value for the local populations from some areas of the Cerrado and Caatinga Biomes only have their chromosome number known, such as Caesalpinia bracteosa Tul. and Caesalpinia pyramidalis Tul. As for Caesalpinia laxiflora Tul. and Cenostigma macrophyllum Tul., which are also native to the Caatinga, not even the chromosome number is known. The chromosome number $2 \mathrm{n}=24$ is found in C. echinata Lam. (Beltrão 
and Guerra, 1990). However, its karyomorphology remains unreported in the literature. This species has a high economic value and, because of that, it has been overexploited; its natural habitat (Atlantic Forest) is also very devastated (Rocha, 2004; Rondon et al., 2006). Today, $C$. echinata is endangered (Varty, 1998). This species has a genetic diversity compatible with the existence of botanical varieties, subspecies, or complex of species (Juchum et al., 2008), but the few remaining natural populations are structured (Cardoso et al., 1998; Melo et al., 2007). Furthermore, there is still devastation of forest fragments where some of these populations live.

Despite $2 \mathrm{n}=24$ being a common chromosome number in Caesalpinia, important data have been obtained from the karyomorphological analysis via classical cytogenetic techniques, which allow for species characterization and can contribute to the understanding of this clade. Thus, the different karyomorphological parameters and the comparative analysis of karyotype asymmetry have that potential. It is known that more symmetrical karyotypes show a high total form percent (TF\%), a chromosomal asymmetry parameter (Huziwara, 1962), or low karyotype asymmetry index (AI) (Paszko, 2006). These two asymmetry parameters have been adopted to analyze different taxonomic levels. AI was seen to be quite informative in studies of infra-generic karyotypic heterogeneity, as demonstrated for eight Calamagrostis accessions (Poaceae) (Paszko, 2006) and six Coffea species (Pierozzi et al., 2012). As demonstrated in the analysis of 217 species representing different Liliaceae genera (Peruzzi et al., 2009), AI is perceived as a suitable parameter for suprageneric evolutionary studies.

The number and morphology of chromosomes are the distinctions that are more frequently used in cytogenetics (Biondo et al., 2005). A direct comparative analysis of cytogenetic data in closely related species allows pinpointing the unique features of each species, as well as those that are common to all or to most of them (Guerra, 1990). In recent studies, AI and its components were observed to be suitable for comparative analysis at different taxa, encouraging us to use it in analysis of different Caesalpinia s.l. and Cenostigma species. Accordingly, the chromosome number and morphometric characteristics of five species were determined in an attempt to provide input to cytotaxonomic studies on Caesalpinieae from Caatinga. Moreover, Paszko's AI and its components were used to investigate the karyotypic heterogeneity of 14 Caesalpinia s.l. and Cenostigma species.

\section{MATERIAL AND METHODS}

\section{Sample collection and preparation of slides}

The original cytogenetic data of five Brazilian endemic tree species were obtained as a complement to our previous karyomorphological studies (Rodrigues et al., 2012). Samples of each species were collected at different localities of Bahia State: C. bracteosa in Oliveira dos

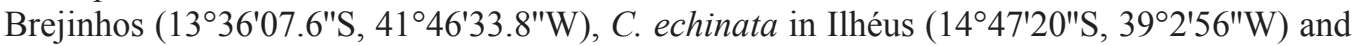
Feira de Santana $\left(12^{\circ} 16^{\prime} 01^{\prime \prime S}, 38^{\circ} 58^{\prime} 1 " \mathrm{~W}\right)$, C. laxiflora and C. pyramidalis in Bom Jesus da Lapa (13 $\left.19^{\prime} 0.9^{\prime \prime} \mathrm{S}, 43^{\circ} 20^{\prime} 14.8^{\prime \prime} \mathrm{W}\right)$. As for C. echinata, a third sample was collected in Recife, Pernambuco $\left(8^{\circ} 2^{\prime} 32.82^{\prime \prime} \mathrm{S}, 34^{\circ} 53^{\prime} 55.9^{\prime \prime} \mathrm{W}\right)$. C. echinata was a rare species in nature, and it was collected from urban parks, whereas all the others species were collected from their natural occurrence sites. In turn, C. macrophyllum Tul. was obtained in an area of urban expansion located $5 \mathrm{~km}$ from Ibotirama $\left(12^{\circ} 09^{\prime} 19.5^{\prime \prime} \mathrm{S}, 43^{\circ} 10^{\prime} 03.9^{\prime \prime} \mathrm{W}\right)$.

The identification of samples was confirmed by comparing the materials available at the herbarium of UESC, and a copy of each species was kept in the herbarium (voucher: C. bracteosa 
16043, C. echinata 2929, C. laxiflora 16038, C. pyramidalis 16039, and C. macrophyllum 16041). Botanical samples were likewise kept in the Herbarium of UEFS (Feira de Santana, BA).

Apical samples of roots were used to prepare the slides as described before (Rodrigues et al., 2012).

\section{Analysis of cytogenetic data}

Short arm (SA), long arm (LA), and satellites (SAT) were measured using the Image Tool 3.0 software. From this data, we calculated the ratio between chromosome arms ( $r=$ LA / SA), total chromosome length ( $\mathrm{TCL}=\mathrm{SA}+\mathrm{LA}+\mathrm{SAT})$, the relative length of each chromosome, the average chromosome length $(\chi=\Sigma \mathrm{TCL} /$ number of chromosomes $)$, the haploid lot length (HLL), the AI for TF\% (Huziwara, 1962), and the AI for A of Romero Zarco (1986). The karyotypic formula was established, and the satellites were classified according to the pattern used before (Rodrigues et al., 2012). The karyograms and ideograms were obtained with the help of the Adobe Photoshop CS4.0 program.

Morphometric data were statistically analyzed in a completely randomized design with five replicates. Statistical analyses were performed using the Sisvar software (Ferreira, 2003). Analysis of variance (ANOVA) was applied to assess differences in the mean chromosome length of species and between accessions of the same species, as well as variations in chromosome length from the first to the twelfth chromosome pair of each species. Means were compared by applying the Scott-Knott test at 5\% probability.

\section{Analysis of karyotypic heterogeneity in Caesalpinia}

The 14 Caesalpinia s.l. and Cenostigma species were tested in terms of karyotype heterogeneity according to the Paszko's AI estimates and based on scatter plots of the variation sources comprising this parameter (Paszko, 2006). Most of the data are derived from cytogenetic studies carried out following the same methodological procedures (five species described in the previous section and five species analyzed by Rodrigues et al., 2012). As for Caesalpinia crista L., measurements were collected from karyograms available in the literature, whereas the values were standardized based on the HLL calculated by Jena et al. (2004). With regard to the other three species, measurements were directly taken from the respective ideograms in previous results (Cangiano and Bernardello, 2005).

Most of the species analyzed in this study were previously placed in new combinations of genera segregated from Caesalpinia s.l. (Lewis, 1998; Gasson et al., 2009; Queiroz, $2009,2010)$. Despite the high taxonomic variation of Caesalpinia clade, sampling was restricted to those species whose detailed karyomorphological data have been obtained so far.

\section{RESULTS}

\section{Morphometric analyses of five Brazilian Caesalpinia species}

In this study, the observed chromosome number in C. bracteosa, C. echinata, C. laxiflora, C. pyramidalis, and C. macrophyllum was $2 \mathrm{n}=24$ (Figures 1 and 2). This chromosome number is commonly found in the Caesalpinia species. 


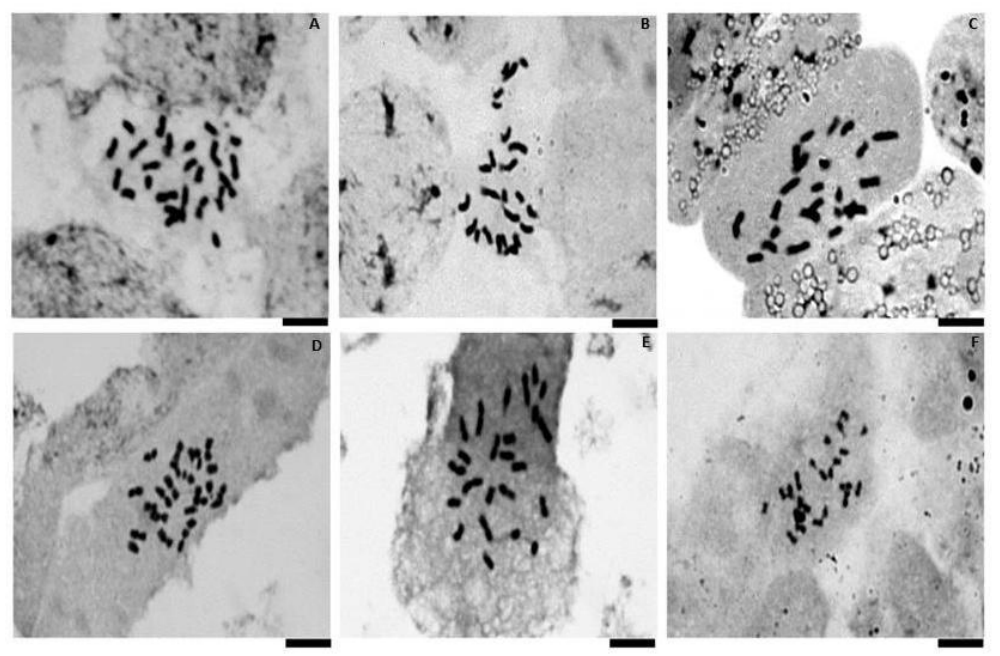

Figure 1. Conventional staining in the mitotic metaphases of Caesalpinia L. s.l. species. A. C. bracteosa Tul.; B. $C$. echinata Lam. (Ilhéus); C. C. echinata Lam. (Recife); D. C. laxiflora Tul.; E. C. pyramidalis Tul.; F. Cenostigma macrophyllum Tul. Bar $=10 \mu \mathrm{m}$.

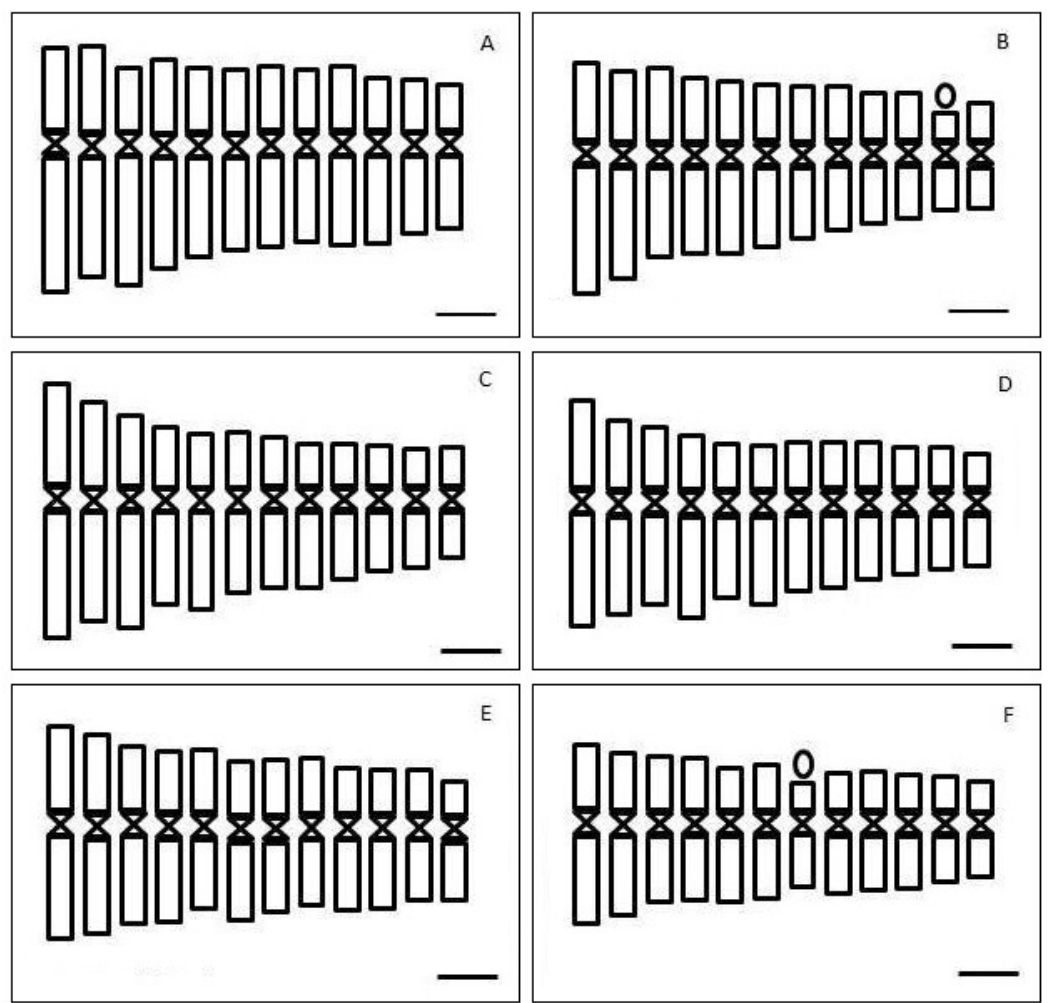

Figure 2. Ideograms of Caesalpinia L. s.l. species. A. C. bracteosa Tul.; B. C. laxiflora Tul.; C. C. echinata Lam. (Ilhéus/ Feira de Santana); D. C. echinata Lam. (Recife); E. C. pyramidalis Tul.; F. Cenostigma macrophyllum Tul. Bar $=1 \mathrm{~cm}$. 
The values of $\chi$ reveals little variation among the five Caesalpinia species examined (Tables 1 and 2); $\chi$ ranged from $3.12 \mu \mathrm{m}$ in C. bracteosa to 2.03 in Caesalpinia sp, but it remained nearly constant between $C$. laxiflora and $C$. pyramidalis $(2.52$ and $2.51 \mu \mathrm{m}$, respectively) and between the accessions of $C$. echinata from different locations $(2.40 \mu \mathrm{m}$ in Ilhéus, $2.41 \mu \mathrm{m}$ in Feira de Santana, and $2.43 \mu \mathrm{m}$ in Recife).

Table 1. Karyomorphological data regarding the metaphases of Caesalpinia s.l. species.

\begin{tabular}{|c|c|c|c|c|c|c|c|c|c|c|c|c|c|}
\hline \multirow[t]{2}{*}{ Species* } & \multirow[t]{2}{*}{ Data } & \multicolumn{12}{|c|}{ Chromosome pair } \\
\hline & & 1 & 2 & 3 & 4 & 5 & 6 & 7 & 8 & 9 & 10 & 11 & 12 \\
\hline \multirow[t]{7}{*}{ bra } & SA & 1.56 & 1.65 & 1.23 & 1.40 & 1.23 & 1.21 & 1.23 & 1.24 & 1.16 & 1.00 & 0.99 & 0.88 \\
\hline & LA & 2.58 & 2.28 & 2.47 & 2.12 & 1.92 & 1.76 & 1.72 & 1.70 & 1.63 & 1.66 & 1.46 & 1.35 \\
\hline & TCL & 4.14 & 3.93 & 3.70 & 3.52 & 3.15 & 2.98 & 2.96 & 2.94 & 2.79 & 2.66 & 2.45 & 2.23 \\
\hline & $\mathrm{SD}( \pm)$ & 0.95 & 0.92 & 0.91 & 0.40 & 0.56 & 0.74 & 0.70 & 0.67 & 0.58 & 0.72 & 0.36 & 0.57 \\
\hline & S-K & $\mathrm{a}$ & $\mathrm{a}$ & $\mathrm{a}$ & $\mathrm{a}$ & $\mathrm{b}$ & $\mathrm{b}$ & $\mathrm{b}$ & $\mathrm{b}$ & $\mathrm{b}$ & $\mathrm{b}$ & $\mathrm{b}$ & $\mathrm{b}$ \\
\hline & $\mathrm{r}$ & 1.65 & 1.38 & 2.00 & 1.51 & 1.56 & 1.45 & 1.40 & 1.37 & 1.40 & 1.66 & 1.47 & 1.53 \\
\hline & $\mathrm{CM}$ & $\mathrm{m}$ & $\mathrm{m}$ & $\mathrm{sm}$ & $\mathrm{m}$ & $\mathrm{m}$ & $\mathrm{m}$ & $\mathrm{m}$ & $\mathrm{m}$ & $\mathrm{m}$ & $\mathrm{m}$ & $\mathrm{m}$ & $\mathrm{m}$ \\
\hline \multirow[t]{7}{*}{ echI } & SA & 1.70 & 1.25 & 1.14 & 0.92 & 1.06 & 0.83 & 0.86 & 0.87 & 0.89 & 0.70 & 0.75 & 0.60 \\
\hline & LA & 1.91 & 1.72 & 1.78 & 1.82 & 1.46 & 1.61 & 1.39 & 1.36 & 1.13 & 1.11 & 0.96 & 0.90 \\
\hline & TCL & 3.61 & 3.06 & 2.92 & 2.75 & 2.52 & 2.43 & 1.25 & 1.22 & 2.02 & 1.81 & 1.71 & 1.50 \\
\hline & $\mathrm{SD}( \pm)$ & 0.66 & 0.32 & 0.32 & 0.28 & 0.40 & 0.39 & 0.32 & 0.27 & 0.22 & 0.20 & 0.17 & 0.24 \\
\hline & S-K & $\mathrm{a}$ & $\mathrm{b}$ & $\mathrm{b}$ & $\mathrm{b}$ & $\mathrm{c}$ & $\mathrm{c}$ & $\mathrm{c}$ & $\mathrm{c}$ & $\mathrm{d}$ & $\mathrm{d}$ & $\mathrm{d}$ & $\mathrm{d}$ \\
\hline & $\mathrm{r}$ & 1.12 & 1.27 & 1.56 & 1.98 & 1.38 & 1.94 & 1.61 & 1.57 & 1.27 & 1.59 & 1.27 & 1.49 \\
\hline & $\mathrm{CM}$ & $\mathrm{m}$ & $\mathrm{m}$ & $\mathrm{m}$ & $\mathrm{sm}$ & $\mathrm{m}$ & $\mathrm{sm}$ & $\mathrm{m}$ & $\mathrm{m}$ & $\mathrm{m}$ & $\mathrm{m}$ & $\mathrm{m}$ & $\mathrm{m}$ \\
\hline \multirow[t]{7}{*}{$e c h F$} & SA & 1.71 & 1.54 & 1.21 & 1.14 & 0.80 & 0.85 & 0.82 & 0.76 & 0.81 & 0.68 & 0.70 & 0.66 \\
\hline & LA & 2.14 & 1.94 & 1.74 & 1.58 & 1.70 & 1.45 & 1.35 & 1.32 & 1.17 & 1.11 & 0.93 & 0.82 \\
\hline & TCL & 3.85 & 3.48 & 2.95 & 2.72 & 2.50 & 2.31 & 2.17 & 2.08 & 1.98 & 1.78 & 1.63 & 1.48 \\
\hline & $\mathrm{SD}( \pm)$ & 0.58 & 0.53 & 0.40 & 0.25 & 0.17 & 0.21 & 0.15 & 0.14 & 0.12 & 0.12 & 0.15 & 0.09 \\
\hline & S-K & $\mathrm{a}$ & $\mathrm{a}$ & $\mathrm{b}$ & $\mathrm{b}$ & $\mathrm{c}$ & $\mathrm{c}$ & $\mathrm{c}$ & $\mathrm{c}$ & $\mathrm{c}$ & $\mathrm{d}$ & $\mathrm{d}$ & $\mathrm{d}$ \\
\hline & $\mathrm{r}$ & 1.24 & 1.25 & 1.43 & 1.38 & 2.13 & 1.69 & 1.63 & 1.73 & 1.44 & 1.64 & 1.32 & 1.23 \\
\hline & $\mathrm{CM}$ & $\mathrm{m}$ & $\mathrm{m}$ & $\mathrm{m}$ & $\mathrm{m}$ & $\mathrm{sm}$ & $\mathrm{m}$ & $\mathrm{m}$ & $\mathrm{sm}$ & $\mathrm{m}$ & $\mathrm{m}$ & $\mathrm{m}$ & $\mathrm{m}$ \\
\hline \multirow[t]{7}{*}{$e c h R$} & SA & 1.72 & 1.54 & 1.13 & 0.95 & 0.87 & 0.98 & 0.92 & 0.72 & 0.75 & 0.75 & 0.65 & 0.67 \\
\hline & LA & 2.20 & 2.03 & 2.13 & 1.57 & 1.64 & 1.35 & 1.27 & 1.39 & 1.19 & 1.04 & 0.94 & 0.79 \\
\hline & TCL & 3.92 & 3.57 & 2.27 & 2.53 & 2.51 & 2.34 & 2.20 & 2.11 & 1.95 & 1.79 & 1.59 & 1.46 \\
\hline & $\mathrm{SD}( \pm)$ & 0.63 & 0.80 & 0.88 & 0.32 & 0.50 & 0.38 & 0.26 & 0.30 & 0.24 & 0.26 & 0.36 & 0.33 \\
\hline & S-K & $\mathrm{a}$ & $\mathrm{a}$ & $\mathrm{a}$ & $\mathrm{b}$ & $\mathrm{b}$ & $\mathrm{b}$ & $\mathrm{b}$ & $\mathrm{b}$ & $\mathrm{c}$ & $\mathrm{c}$ & $\mathrm{c}$ & $\mathrm{c}$ \\
\hline & $\mathrm{r}$ & 1.28 & 1.31 & 1.87 & 1.65 & 1.88 & 1.37 & 1.38 & 1.92 & 1.57 & 1.38 & 1.43 & 1.17 \\
\hline & $\mathrm{CM}$ & $\mathrm{m}$ & $\mathrm{m}$ & $\mathrm{sm}$ & $\mathrm{m}$ & $\mathrm{sm}$ & $\mathrm{m}$ & $\mathrm{m}$ & $\mathrm{sm}$ & $\mathrm{m}$ & $\mathrm{m}$ & $\mathrm{m}$ & $\mathrm{m}$ \\
\hline \multirow[t]{7}{*}{$\operatorname{lax}$} & SA & 1.47 & 1.34 & 1.41 & 1.23 & 1.15 & 1.07 & 1.04 & 1.01 & 0.91 & 0.82 & 0.85 & 0.69 \\
\hline & LA & 2.45 & 2.11 & 1.70 & 1.64 & 1.63 & 1.50 & 1.33 & 1.22 & 1.09 & 0.99 & 0.95 & 0.78 \\
\hline & TCL & 3.92 & 3.45 & 3.11 & 2.87 & 2.78 & 2.57 & 2.37 & 2.23 & 2.00 & 1.81 & 1.80 & 1.47 \\
\hline & $\mathrm{SD}( \pm)$ & 0.14 & 0.24 & 0.21 & 0.24 & 0.25 & 0.17 & 0.25 & 0.20 & 0.18 & 0.23 & 0.18 & 0.12 \\
\hline & S-K & $\mathrm{a}$ & $\mathrm{b}$ & $\mathrm{c}$ & $\mathrm{d}$ & $\mathrm{d}$ & $\mathrm{e}$ & $\mathrm{e}$ & $\mathrm{e}$ & $\mathrm{f}$ & $\mathrm{f}$ & $\mathrm{g}$ & $\mathrm{g}$ \\
\hline & $\mathrm{r}$ & 1.66 & 1.57 & 1.20 & 1.33 & 1.41 & 1.40 & 1.27 & 1.20 & 1.19 & 1.20 & 1.11 & 1.13 \\
\hline & $\mathrm{CM}$ & $\mathrm{m}$ & $\mathrm{m}$ & $\mathrm{m}$ & $\mathrm{m}$ & $\mathrm{m}$ & $\mathrm{m}$ & $\mathrm{m}$ & $\mathrm{m}$ & $\mathrm{m}$ & $\mathrm{m}$ & $\mathrm{m}$ & $\mathrm{m}$ \\
\hline \multirow[t]{7}{*}{ pyr } & SA & 1.61 & 1.49 & 1.23 & 1.16 & 1.20 & 1.04 & 1.06 & 1.05 & 0.87 & 0.83 & 0.84 & 0.66 \\
\hline & LA & 1.94 & 1.79 & 1.67 & 1.58 & 1.31 & 1.47 & 1.31 & 1.25 & 1.32 & 1.32 & 1.16 & 1.09 \\
\hline & TCL & 3.55 & 3.28 & 2.90 & 2.74 & 2.51 & 2.51 & 2.37 & 2.30 & 2.19 & 2.15 & 2.00 & 1.75 \\
\hline & $\mathrm{SD}( \pm)$ & 0.59 & 0.58 & 0.54 & 0.66 & 0.67 & 0.53 & 0.47 & 0.44 & 0.35 & 0.34 & 0.34 & 0.38 \\
\hline & S-K & $\mathrm{a}$ & $\mathrm{a}$ & $\mathrm{b}$ & $\mathrm{b}$ & $\mathrm{c}$ & $\mathrm{c}$ & $\mathrm{c}$ & $\mathrm{c}$ & $\mathrm{c}$ & $\mathrm{c}$ & $\mathrm{c}$ & $\mathrm{c}$ \\
\hline & $\mathrm{r}$ & 1.20 & 1.20 & 1.36 & 1.36 & 1.10 & 1.41 & 1.24 & 1.19 & 1.52 & 1.59 & 1.38 & 1.65 \\
\hline & $\mathrm{CM}$ & $\mathrm{m}$ & $\mathrm{m}$ & $\mathrm{m}$ & $\mathrm{m}$ & $\mathrm{m}$ & $\mathrm{m}$ & $\mathrm{m}$ & $\mathrm{m}$ & $\mathrm{m}$ & $\mathrm{m}$ & $\mathrm{m}$ & $\mathrm{m}$ \\
\hline \multirow[t]{7}{*}{$m a c$} & SA & 1.24 & 1.10 & 1.04 & 1.01 & 0.83 & 0.86 & 0.92 & 0.72 & 0.68 & 0.65 & 0.63 & 0.55 \\
\hline & LA & 1.70 & 1.50 & 1.26 & 1.23 & 1.28 & 1.19 & 1.10 & 1.10 & 1.01 & 0.89 & 0.84 & 0.78 \\
\hline & TCL & 2.94 & 2.60 & 2.30 & 2.24 & 2.11 & 2.05 & 2.02 & 1.82 & 1.69 & 1.54 & 1.47 & 1.33 \\
\hline & $\mathrm{SD}( \pm)$ & 0.75 & 0.66 & 0.54 & 0.52 & 0.57 & 0.58 & 0.62 & 0.47 & 0.47 & 0.50 & 0.32 & 0.19 \\
\hline & S-K & $\mathrm{a}$ & $\mathrm{a}$ & $\mathrm{a}$ & $\mathrm{a}$ & $\mathrm{a}$ & $\mathrm{a}$ & $\mathrm{b}$ & $\mathrm{b}$ & $\mathrm{b}$ & $\mathrm{b}$ & $\mathrm{b}$ & $\mathrm{b}$ \\
\hline & $\mathrm{r}$ & 1.37 & 1.36 & 1.21 & 1.21 & 1.54 & 1.38 & 1.20 & 1.52 & 1.48 & 1.32 & 1.33 & 1.41 \\
\hline & $\mathrm{CM}$ & M & $\mathrm{m}$ & $\mathrm{m}$ & $\mathrm{m}$ & $\mathrm{m}$ & $\mathrm{m}$ & $\mathrm{m}$ & $\mathrm{m}$ & $\mathrm{m}$ & $\mathrm{m}$ & $\mathrm{m}$ & $\mathrm{m}$ \\
\hline
\end{tabular}

Mean values in $\mu \mathrm{m}$ of the short arm (SA), long arm (LA) and total chromosome length (TCL). Standard deviation of TCL (SD), Scott-Knott test regarding the average length of each chromosome (S-K), arm ratio (r) and classification of chromosome morphology $(\mathrm{CM})(\mathrm{m}=$ metacentric, $\mathrm{sm}=$ submetacentric). *Name abbreviations of Caesalpinia L s.1. species: bra $=C$. bracteosa Tul.; echI $=C$. echinata Lam. from Ilhéus; echF $=C$. echinata from Feira de Santana; echR $=$ C. echinata from Recife; lax $=$ C. laxiflora Tul.; pyr $=$ C. pyramidalis Tul.; mac $=$ Cenostigma macrophyllum Tul. 
Table 2. Karyotype parameters in Caesalpinia L. s.1.

\begin{tabular}{lccccc}
\hline Species name (sampling locations) & HLL $(\mu \mathrm{m})$ & $\chi(\mu \mathrm{m})$ & $\mathrm{TF} \%$ & $\mathrm{~A}_{1}$ & $\mathrm{KF}$ \\
\hline C. bracteosa Tul. & 37.47 & $3.12 \pm 0.49$ & 37.47 & 0.34 & $11 \mathrm{~m}+1 \mathrm{sm}$ \\
C. echinata Lam. (Ilhéus) & 28.83 & $2.40 \pm 0.29$ & 40.45 & 0.32 & $10 \mathrm{~m}+2 \mathrm{sm}$ \\
C. echinata Lam. (Feira de Santana) & 28.97 & $2.41 \pm 0.19$ & 40.42 & 0.32 & $10 \mathrm{~m}+2 \mathrm{sm}$ \\
C. echinata Lam. (Recife) & 29.26 & $2.43 \pm 0.42$ & 39.95 & 0.32 & $9 \mathrm{~m}+3 \mathrm{sm}$ \\
C. laxiflora Tul. & 30.26 & $2.52 \pm 0.14$ & 42.52 & 0.23 & $12 \mathrm{~m}$ \\
C. pyramidalis Tul. & 30.20 & $2.51 \pm 0.46$ & 43.04 & 0.25 & $12 \mathrm{~m}$ \\
Cenostigma macrophyllum Tul. & 24.36 & $2.03 \pm 0.30$ & 40.20 & 0.27 & $12 \mathrm{~m}$ \\
\hline
\end{tabular}

Haploid lot length (HLL), average length of chromosomes $(\chi)$, asymmetry index of total form percent (TF\%), intrachromosomal asymmetry indexes $\left(\mathrm{A}_{1}\right)$, and karyotype formula $(\mathrm{KF})$, where $\mathrm{m}$ is metacentric and $\mathrm{sm}$ is submetacentric.

The variation in chromosome size reached $53.8 \%$ in $C$. bracteosa Tul., $37.5 \%$ in $C$. laxiflora, $49.2 \%$ in C. pyramidalis, $45.2 \%$ in C. macrophyllum, $41.55 \%$ in the C. echinata from Ilhéus, $38.44 \%$ in the C. echinata Lam. from Feira de Santana, and $37.25 \%$ in the $C$. echinata from Recife. C. bracteosa has the largest HLL as compared to C. macrophyllum.

A pair of chromosomes in satellite form was only observed in C. laxiflora and C. macrophyllum (Table 2). There was also the minisatellite-type, sized 0.43 and $0.46 \mu \mathrm{m}$, in these species, respectively. Nevertheless, the satellites were located on the short arms of separate chromosome pairs. In C. laxiflora, the satellite is found at the chromosome pair number 10, whereas in C. macrophyllum, it is located at the pair number 7.

For the seven populations analyzed, the three different karyotypic formulas determined and the TF\% values showed that these populations had quite symmetrical karyotypes (Tables 1 and 2). Exclusively metacentric chromosomes were observed in C. laxiflora, $C$. pyramidalis, and C. macrophyllum (formula $12 \mathrm{~m}$ ). Only the third chromosome pair was seen to be submetacentric in C. bracteosa $(11 \mathrm{~m}+1 \mathrm{sm})$.

Depending on the locality examined, two or three pairs of submetacentric chromosomes were observed in C. echinata. In addition, there were variations in the pair where they were found $(10 \mathrm{~m}+2 \mathrm{sm}$ in Ilhéus and Feira de Santana; $9 \mathrm{~m}+3 \mathrm{sm}$ in Recife). The highest TF\% was $43.04 \%$ in C. pyramidalis, whereas the lowest value was $37.47 \%$ in C. bracteosa. The variation in TF\% between the species was $13 \%$.

ANOVA revealed a significant difference $(\mathrm{P}<0.05)$ relative to the average chromosome size between the species (Table 3). Yet, there were no significant differences regarding this trait in C. echinata between the sampling localities (Table 4). ANOVA also revealed a significant difference relative to the $\chi$ within each species (Table 5). The coefficient of variation (CV) in all of the analyses ranged from $8.33 \%$ in C. laxiflora to $26.59 \%$ in C. bracteosa.

Table 3. Summary of ANOVA regarding the average length of chromosomes between Caesalpinia L. s.l. species: C. bracteosa Tul., C. echinata Lam. (Ilhéus, Feira de Santana and Recife), C. laxiflora Tul., C. pyramidalis Tul. and Caesalpinia $\mathrm{sp}(2 \mathrm{n}=24)$.

\begin{tabular}{lcc}
\hline Variation sources & d.f. & MS \\
\hline Taxa & 6 & 0.5203 \\
Error & 28 & 0.1466 \\
CV $(\%)$ & & 15.38 \\
\hline
\end{tabular}

d.f. $=$ degrees of freedom; MS = mean square $\mathrm{CV}=$ coefficient of variation. Significant at $1 \%$ probability by $\mathrm{F}$ test. 
Table 4. Summary of ANOVA for the average chromosome length $(\chi)$ of Caesalpinia echinata Lam. regarding the three sampling places.

\begin{tabular}{lccc}
\hline Variation sources & d.f. & MS & F \\
\hline Taxa & 2 & 0.0017 & $0.0170^{\text {ns }}$ \\
Error & 12 & 0.0999 & \\
CV $(\%)$ & & 13.09 & \\
\hline
\end{tabular}

d.f. $=$ degrees of freedom; $\mathrm{MS}=$ mean square; $\mathrm{CV}=$ coefficient of variation. ${ }^{\text {ns Not }}$ significant at $1 \%$ probability by the F test.

Table 5. Summary of ANOVA regarding the length of chromosomes in Caesalpinia L. s.1. species.
\begin{tabular}{lcccccccc}
\hline Variation sources & d.f. & \multicolumn{7}{c}{ MS } \\
\cline { 2 - 9 } & & $b r a$ & $e c h \mathrm{I}$ & $e c h \mathrm{~F}$ & ech $\mathrm{R}$ & lax & pyr & sp 1 \\
\hline Taxa & 11 & 1.0000 & 1.8911 & 2.6573 & 3.0364 & 2.7597 & 1.3693 & 0.9070 \\
Error & 48 & 0.2921 & 0.1174 & 0.0873 & 0.2418 & 0.0441 & 0.2575 & 0.2629 \\
CV (\%) & 26.59 & 14.25 & 12.23 & 20.15 & 8.33 & 20.14 & 25.59 \\
\hline
\end{tabular}

d.f. $=$ degrees of freedom; MS = mean square; $C V=$ coefficient of variation. Species name abbreviations are indicated in Table 1 . Significant at $1 \%$ probability by the $\mathrm{F}$ test.

\section{Chromosomal heterogeneity in Caesalpinia group}

Interchromosomal variations regarding the position of the centromere $\left(\mathrm{CV}_{\mathrm{CI}}\right)$ and chromosome size $\left(\mathrm{CV}_{\mathrm{CL}}\right)$, as well as the estimated $\mathrm{AI}$ values, revealed that there is chromosomal diversity among Caesalpinia and Cenostigma species (Figure 3A). Among the 14 species analyzed for karyotypic heterogeneity, only 8 had published karyomorphological data. The scatter plot of $\mathrm{CV}_{\mathrm{CI}} \times \mathrm{CV}_{\mathrm{CL}}$ shows that the $\mathrm{AI}$ values were equally influenced by these two variation components in most species except $C$. echinata, $C$. laxiflora, and $C$. macrophyllum. In the ranking of species based on AI, three groups are observed (Figure 3B): a group of species with symmetrical karyotypes [C. paraguariensis (D. Parodi) Burkart and C. gilliesii (Wall. ex Hook.) Benth.], a group with an asymmetrical karyotype (Caesalpinia calycina Benth.), and a group with all of the other species, which display intermediate and gradual AI values.

The components of variation that integrate $\mathrm{AI}\left(\mathrm{CV}_{\mathrm{CI}}\right.$ and $\left.\mathrm{CV}_{\mathrm{CL}}\right)$ showed no significant correlation related to the HLL $\left(\mathrm{R}^{2}=36.3\right.$ and 12.4, respectively). Furthermore, there was no significant correlation between the parameters of chromosome asymmetry $\mathrm{AI}$ and $\mathrm{TF} \%\left(\mathrm{R}^{2}=\right.$ $31.9)$ relative to the 14 species analyzed. Nine of the 14 species analyzed in this study are part of re-established genera from Caesalpinia s.l. (Table 6).

\section{DISCUSSION}

\section{Chromosome diversity}

The Caesalpinia s.1. and Cenostigma species that were karyomorphometrically evalu- 

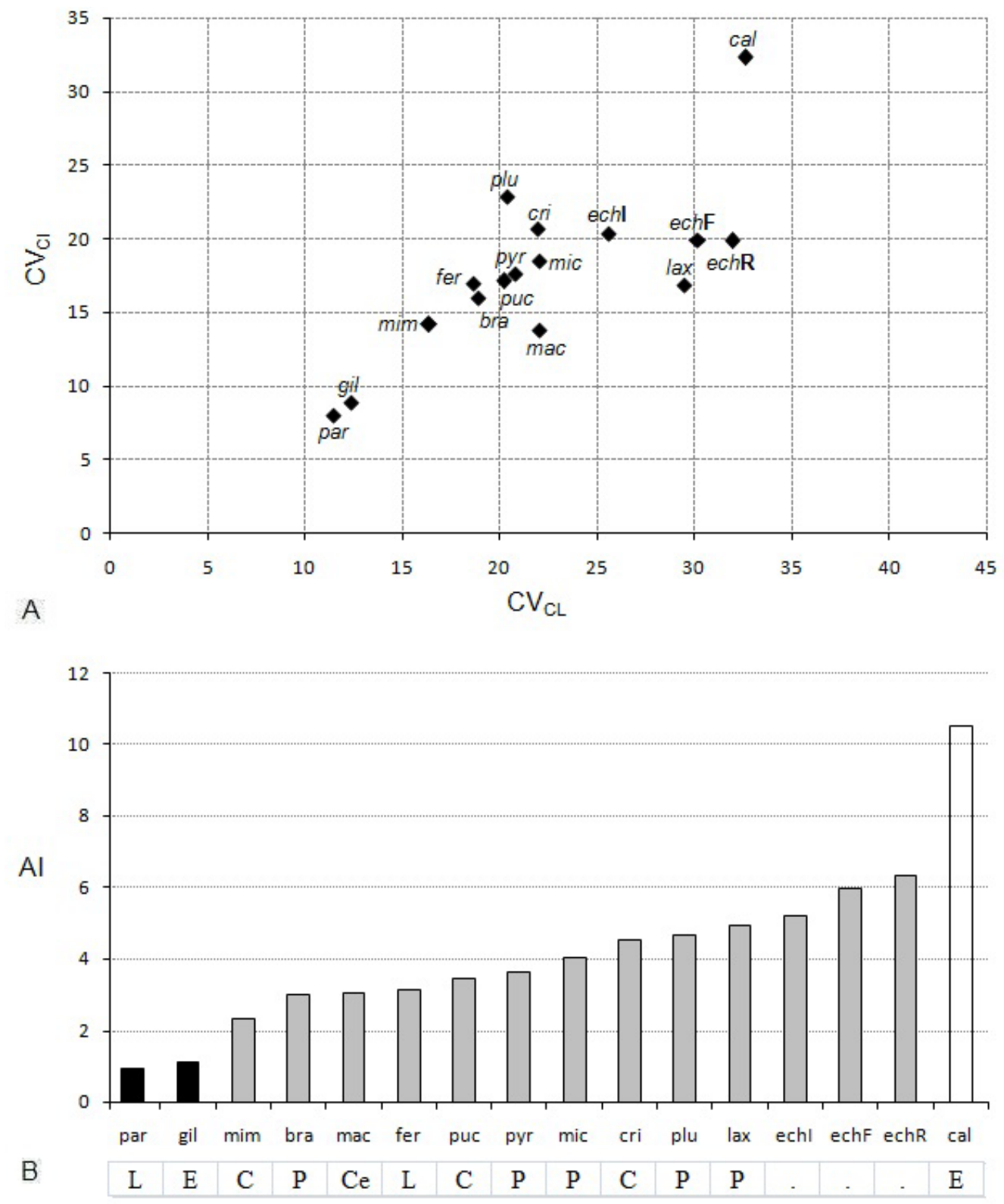

Figure 3. Scatter diagram of chromosome characteristics for Caesalpinia L. s.l. and Cenostigma species. Abbreviations of species names: bra $=C$. bracteosa; $\mathrm{cal}=C$. calycina $;$ echI $=C$. echinata from Ilhéus; echF $=C$. echinata from Feira de Santana; echR $=C$. echinata from Recife; fer $=C$. ferrea; gil $=C$. gilliesii; lax $=$ C. laxiflora; mic $=C$. microphylla $; \min =C$. mimosifolia $; \mathrm{par}=C$. paraguariensis $;$ pul $=C$. pulcherrima $;$ plu $=C$. pluviosa $;$ pyr $=$ C. pyramidalis; $\mathrm{mac}=$ Cenostigma macrophyllum. A. Coefficient of variation $(\mathrm{CV})$ of the chromosome length $\left(\mathrm{CV}_{\mathrm{CI}}\right)$ against the centromeric index $\left(\mathrm{CV}_{\mathrm{CI}}\right)$ parameters. B. Caesalpinia s.1. species asymmetry index as for Paszko (2006) where $\mathrm{L}=$ Libidibia $; \mathrm{E}=$ Erythrostemon; $\mathrm{PE}=$ Poincianella-Erythrostemon group; $\mathrm{C}=$ Caesalpinia s.s.; $\mathrm{P}$ = Poincianella $; \mathrm{Ce}=$ Cenostigma . 
Table 6. Coding adopted for the different species in the present study, species names and their new combinations of genera in Caesalpinia s.1.

\begin{tabular}{|c|c|c|c|}
\hline Code & Species of Caesalpinia s.1. and Cenostigma & New combinations of species names & Ref \\
\hline par & Caesalpinia paraguarienses (D.Parodi) Burkat. & Libidibia paraguariensis (D. Parodi) G.P. Lewis & 1 \\
\hline gil & Caesalpinia gilliesii (Hook.) Benth. & Erythrostemon gilliesii (Hook.) D. Dietr. & 2 \\
\hline $\operatorname{mim}$ & Caesalpinia mimosifolia Griseb. & - & 1 \\
\hline bra & Caesalpinia bracteosa Tul. & Poincianella bracteosa (Tul.) L.P. Queiroz & 3 \\
\hline mac & Cenostigma macrophylum Tul. & - & 1 \\
\hline fer & Caesalpinia ferrea var. leiostachya Benth. & Libidibia ferrea var. leiostachya (Benth.) L.P. Queiroz & 4 \\
\hline puc & Caesalpinia pulcherrima Sw. & - & 1 \\
\hline pyr & Caesalpinia pyramidalis Tul. & Poincianella pyramidalis var. diversifolia (Benth.) L.P. Queiroz & 4 \\
\hline mic & Caesalpinia microphylla Mart. & Poincianella microphylla (Mart. ex G. Don) L.P. Queiroz & 3 \\
\hline cri & Caesalpinia crista L. & - & 1 \\
\hline plu & Caesalpinia pluviosa var. phetophoroides Bent. & Poincianella pluviosa var. peltophoroides (Benth.) L.P. Queiroz & 4 \\
\hline $\operatorname{lax}$ & Caesalpinia laxiflora Tul. & Poincianella laxiflora (Tul.) L.P. Queiroz & 3 \\
\hline$e c h \mathrm{I}$ & Caesalpinia echinata Lam. & - & 1 \\
\hline$e c h \mathrm{~F}$ & Caesalpinia echinata Lam. & - & 1 \\
\hline$e c h \mathrm{R}$ & Caesalpinia echinata Lam. & - & 1 \\
\hline cal & Caesalpinia calycina Benth. & Erythrostemon calycina (Benth.) L.P. Queiroz & 3 \\
\hline
\end{tabular}

Ref = References: 1 = IPNI (2013); 2 = Manzanilla e Bruneau (2012); 3 = Queiroz (2009); 4 = Queiroz (2010).

ated in this study showed the diploid chromosome number $2 n=24$. The chromosome number of C. laxiflora and C. macrophyllum was cytogenetically described for the first time; the chromosome number of $C$. pyramidalis, C. echinata, and C. bracteosa was confirmed; and the chromosome morphometric data for these five species were described in this research for the first time. Therefore, the data obtained in this research confirmed $2 n=24$ as being common to the Caesalpinia species. Our data was obtained from three different populations of C. echinata and only one population of each of the other species.

In spite of previous reports on tetraploid populations of C. bracteosa with $2 \mathrm{n}=48$ (Alves and Custódio, 1989), this variation was not found in this study, probably because the only population samples were made up of diploid individuals. Among Caesalpinioideae, the diploid chromosome number is variable, and species with $2 \mathrm{n}=20,24,26$, and 28 were already described (Jena et al., 2004; Souza and Benko-Iseppon, 2004; Biondo et al., 2005). However, in spite of the taxonomic diversity of Caesalpinia, the variations in regard to $2 \mathrm{n}=24$ only refer to euploids, suggesting a value of $n=12$. The analysis of meiotic chromosomes should be performed in order to better characterize the peculiarities of the polyploidy that was found in some species. Among the 140 species of Caesalpinia L., the chromosome number is known for only 22 species (14.6\%) (Atchison, 1951; Goldblatt, 1981; Alves and Custódio, 1989; Kumari and Bir, 1989; Beltrão and Guerra, 1990; Lewis, 1998; Jena et al., 2004; Cangiano and Bernardello, 2005; Rodrigues et al., 2012), making the need for more studies on this group clear in order to better distinguish this trait in the diverse genera of Caesalpinioideae.

The analysis of various populations of the same species can reveal cytological stability of the species and even the existence of cryptic species or varieties (Guerra, 1990). Although the analysis of the chromosome number continues to be the principal instrument of cytotaxonomy, the use of more informative techniques such as chromosome morphometry and in situ hybridization can show differences in the structures of the chromosomes among closely related species, revealing more details about the evolution and karyotypic diversity among the Caesalpinia species.

Complete morphometric data were obtained for five more species of Caesalpinia (Ta- 
bles 1 and 2). Previously, this level of detail about the chromosomes of Caesalpinia referred to nine species, only $6.4 \%$ of the known species (Jena et al., 2004; Cangiano and Bernardello, 2005; Rodrigues et al., 2012). By combining the data from these studies and the present study, the morphometric detailing of the chromosomes of 14 species $(10 \%)$ was made available.

The average length of the chromosomes in the species of Caesalpinia that were analyzed varied up to $53.8 \%$, as in C. macrophyllum $(2.03 \mu \mathrm{m})$ relative to C. bracteosa $(3.12$ $\mu \mathrm{m})$. In the studies developed by Jena et al. (2004) and Cangiano and Bernardello (2005), the chromosome size varied from $1.90 \mu \mathrm{m}$ in C. gilliessi, C. paraguarienses, and Caesalpinia mimosifolia Griseb. to $2.07 \mu \mathrm{m}$ in C. crista, a variation of $9.1 \%$. However, in the studies carried out by Rodrigues et al. (2012), this value was greater for the majority of the species that were studied, and chromosome sizes included $2.05 \mu \mathrm{m}$ in C. microphylla Mart., $2.57 \mu \mathrm{m}$ in Caesalpinia pluviosa var. peltophoroides Bent., $2.58 \mu \mathrm{m}$ in Caesalpinia pulcherrima Sw., $2.87 \mu \mathrm{m}$ in Caesalpinia ferrea var. leiostachya Benth., and $3.32 \mu \mathrm{m}$ in C. calycina, indicating variation up to $62 \%$. The average chromosome size that was found in studies carried out among the Caesalpinioideae (Auler and Battistin, 1999; Biondo et al., 2005) varies between 1.80 and 2.50 $\mu \mathrm{m}$, giving $33.3 \%$ variation. Assuming greater variation among genera, our data indicate the need for a more significant sampling of species in this subfamily.

The HLL varied from $37.47 \mu \mathrm{m}$ in C. bracteosa to $24.36 \mu \mathrm{m}$ in C. macrophyllum. These values corroborate the results of Rodrigues (2012), who observed a variation of 39.86 $\mu \mathrm{m}$ in C. calycina to $24.63 \mu \mathrm{m}$ in C. microphylla. The values found by Cangiano and Bernardello (2005) for the HLL varied from 20.67 to $24.74 \mu \mathrm{m}$; these values were slightly lower than our values. However, one should be cautious when making comparisons of HLL between samples that were analyzed by different laboratories that use different technical procedures, such as the type of antimitotic used and pretreatment time to which the roots are submitted before the preparation of the slides.

Among the species of Caesalpinia that were analyzed karyomorphologically, five species had the formula that was defined in this study, three were defined by Cangiano and Bernadello (2005), and the other five were defined by Rodrigues et al. (2012). The four species that showed a karyotype formula that was composed exclusively of metacentric chromosomes (12 m) showed the lowest values for the HLL, which varied from $24.36 \mu \mathrm{m}$ in C. macrophyllum to $30.26 \mu \mathrm{m}$ in C. laxiflora. Of the species with a formula that was not $12 \mathrm{~m}$, only C. echinata had low values of HLL (approximately $29 \mu \mathrm{m}$ ). These species are grouped in Poincianella based on the anatomy of wood (Gasson et al., 2009). C. pluviosa was shown to be distinct among this new genus because its formula had a more derived karyotype characteristic compared to the other species in Poincianella. In fact, a more exhaustive analysis of the chromosome morphometry of C. pluviosa is suggested because it is a species with diverse varieties (Lewis, 1998).

The species with high rates of TF\% asymmetry had all metacentric chromosomes except $C$. echinata from Ilhéus and Feira de Santana, which had two submetacentric chromosomes. Consequently, the species with lower rates of TF\% asymmetry were those that showed a greater number of submetacentric chromosomes than metacentric chromosomes, with the exception of $C$. bracteosa, which had $11 \mathrm{~m}+1 \mathrm{sm}$ and a TF\% of 37.47 . These same standards were observed by Rodrigues et al. (2012), who also observed the presence of a subtelocentric chromosome in C. calycina, which had a karyotype formula of $8 \mathrm{~m}+3 \mathrm{sm}+1 \mathrm{st}$ and a low rate of asymmetry. This shows that the species of Caesalpinia, which showed karyotypes with a low quantity of metacentric chromosomes or with a greater quantity of morphologically different chromosomes, are the species with more asymmetrical karyotypes. 
The karyotypes of Caesalpinia are relatively symmetrical with a predominance of metacentric and submetacentric chromosomes (Kumari and Bir, 1989; Cangiano and Bernardello, 2005; Rodrigues et al., 2012). Nonetheless, morphological dissimilarities were observed between the karyotypes. This was verified in C. laxiflora, C. pyramidalis, and $C$. macrophyllum, which showed a karyotypic formula of $12 \mathrm{~m}$ as previously observed for $C$. microphylla (12 m) (Rodrigues et al., 2012). In turn, C. bracteosa showed a formula of $11 \mathrm{~m}+$ $1 \mathrm{sm}$, whereas $C$. echinata from the cities of Ilhéus and Feira de Santana presented a formula of $10 \mathrm{~m}+2 \mathrm{sm}$ and $C$. echinata from Recife showed a formula of $9 \mathrm{~m}+3 \mathrm{sm}$. The species analyzed in previous studies showed a higher number of submetacentric chromosomes than in this study, reaching $4 \mathrm{~m}+8 \mathrm{sm}$ in C. pluviosa var. peltophoroides. Karyotype asymmetry may be associated with speciation, whereas the symmetrical parameters are the most primitive types (Stebbins, 1971). This can be confirmed here because C. pyramidalis, C. laxiflora, and C. macrophyllum had symmetrical karyotypes $(12 \mathrm{~m})$ and showed the highest AIs (TF\% $=43.04,42.52$, and $40.20 \%$, respectively). These species were therefore found to be more ancient than C. echinata from Ilhéus $(10 \mathrm{~m}+2 \mathrm{sm})$ with a $\mathrm{TF} \%$ of $40.42 \%$, C. echinata from Feira de Santana $(10 \mathrm{~m}+2 \mathrm{sm})$ with a TF\% of $39.90 \%$, C. echinata from Recife $(9 \mathrm{~m}+3 \mathrm{sm})$ with a TF\% of $39.70 \%$, and C. bracteosa $(11 \mathrm{~m}+1 \mathrm{sm})$ with a TF\% of $37.47 \%$. When comparing the $\mathrm{TF} \%$ from the three sites that were evaluated for $C$. echinata, there were almost no differences, indicating some stability.

Of the five species whose morphometric data were obtained in this study, the ones with the lowest values of $\mathrm{A}_{1}$ were seen to tend to have metacentric chromosomes (Tables 1 and 2). The karyotype formula of C. laxiflora, C. pyramidalis, and C. macrophyllum was 12 $\mathrm{m}$, and their respective $\mathrm{A}_{1}$ values were $0.23,0.25$, and 0.27 respectively. On the other hand, $C$. pluviosa was the species with the highest $\mathrm{A}_{1}(0.40)$; yet, this species had the lowest number of metacentric chromosomes $(4 \mathrm{~m}+8 \mathrm{sm})$ among Caesalpinia species (Rodrigues et al., 2012).

Differences relative to the presence and location of satellites were only detectable in two of the five species analyzed. Besides being useful as genetic markers, variations in the number, position, and size of secondary constrictions and satellites are frequently observed in plants, and they can be incorporated or deleted during the evolutionary process. Minisatellites were found on the short arm of metacentric chromosomes in only two of the five species studied; these species only had one pair of chromosomes in satellite formation that was basically the same size: $0.43 \mu \mathrm{m}$ in C. laxiflora and $0.46 \mu \mathrm{m}$ in C. macrophyllum. Yet, the satellites are in different chromosome pairs: on the eleventh chromosome pair of C. laxiflora and on the seventh chromosome pair of C. macrophyllum. Chromosomes with a satellite form are not common in Caesalpinioideae (Kumari and Bir, 1989; Souza and Benko-Iseppon, 2004). In this study, two species had satellites, and all nine of the species previously characterized had satellites in one or more chromosome pairs (Jena et al., 2004; Cangiano and Bernardello, 2005; Rodrigues et al., 2012).

Despite the chromosome number being the same in all the species examined $(2 \mathrm{n}$ $=24$ ) and some Caesalpinia species having the same karyotype formula, combining different karyomorphological data allows species to be differentiated. The use of molecular cytogenetic techniques revealed a need to complement these classic analyses of chromosome morphology. Especially in specimens that have large intraspecific variations, such as C. pluviosa and C. echinata, more comprehensive studies should include the sampling of different populations. 


\section{Karyotypic heterogeneity in Caesalpinia s.l. and Cenostigma}

In taxonomic terms, Caesalpinia is considered very variable. Therefore, different species in this group are being combined into new genera (Lewis, 1998; Gasson et al., 2009; Queiroz, 2009, 2010; IPNI, 2013) (Table 6). In this study, the amplitude of $\mathrm{CV}_{\mathrm{CL}}$ and $\mathrm{CV}_{\mathrm{CI}}$ values tended to be in the same range in some of the new genera. Species from the group Poincianella (C. bracteosa, C. pyramidalis, C. microphylla, C. pluviosa, C. echinata, and C. laxiflora) have intermediate symmetry values. Libidibia species, on the other hand, had karyotypes with low and intermediate AI values (C. paraguariensis and C. ferrea). Only two extreme karyotypes in terms of asymmetry refer to species assigned to the same genus $(C$. gilliessi and C. calycina in Erythrostemon). Hence, this characteristic is generally consistent with the newly proposed combinations of genera in Caesalpinia. In this research, however, the analysis only involves 14 of the 140 Caesalpinia species, revealing the need to further analyze these species to better delineate the karyomorphological types as a function of the newly instated genera.

The karyomorphological data generated in this study, along with those available in the literature, have allowed the parameters of karyotype asymmetry to be determined in 14 Caesalpinia species (Figure 3). $\mathrm{CV}_{\mathrm{CL}}$ was the variation component that most influenced the karyotype asymmetry in C. echinata, C. laxiflora, and C. macrophyllum, which can be confirmed in the higher separation of these three species in relation to the scatter plot diagonal line of $\mathrm{CV}_{\mathrm{CL}} \times \mathrm{CV}_{\mathrm{Cl}}$. These two parameters influenced $\mathrm{AI}$ values from other species in a near-equal manner. In both cases, these two parameters clarified the heterogeneity of karyotypes from all of the species analyzed. The scatter plot based on the variation sources comprising the AI is suitable to compare karyotypes of species from different taxa, as demonstrated in the analysis of different plant families (Paszko, 2006; Peruzzi et al., 2009; Pierozzi et al., 2012).

By analyzing the scatter plot of $\mathrm{CV}_{\mathrm{CI}} \times \mathrm{CV}_{\mathrm{CL}}$, C. calycina was found to have the greatest intrachromosomal variation regarding size and position, showing that this was the karyotype with the highest derivation in the chromosome morphology among the 14 species studied (Figure 3A). Likewise, C. pluviosa had a relatively high variation relative to the position of the centromere, as well as an intermediate level of variation in the chromosome size. Therefore, these two species have the highest karyotype asymmetry. Among the three species that were analyzed by Cangiano and Bernardello (2005), C. paraguariensis and C. gilliessi were the ones with the lowest variations in the centromere position and chromosome size, characteristics considered to be plesiomorphic. The largest variations in chromosome size were observed in C. echinata and C. laxiflora.

An overview of the species analyzed can be made based on the AI values; this parameter associates the contributions of the two variation sources with the variation in karyotype heterogeneity $\left(\mathrm{CV}_{\mathrm{Cl}}\right.$ and $\left.\mathrm{CV}_{\mathrm{CL}}\right)$. In this study, the $\mathrm{AI}$ values revealed three groups (Figure $3 \mathrm{~B}$ ). Group 1 is formed by the species that showed the most asymmetrical karyotype (C. calycina). This characteristic is considered to be evolutionarily derived. Group 2, in turn, is formed by species with more symmetrical karyotypes (C. paraguariensis and C. gilliesii), a characteristic that is considered to be evolutionary basal. The other species examined are found in the intermediate group and showed values with minor differences between each other and great differences from the other two groups.

The two species of Libidibia had intermediate and small AI values (C. ferrea and 
C. paraguariensis, respectively), and these values are close (Figure 3B). The two species of Erythrostemon (C. calycina and C. gilliesii) were divided into different groups according to their contrasting AI values. These AI values indicate an opposite evolutionary trend between their karyotypes. However, C. calycina and C. gilliesii were reassigned to the same genus, Erythrostemon, according to their wood morphology (Gasson et al., 2009) and other traits. Only a pair of species was examined cytogenetically from those genera. Each pair of species consisted of species from geographically distant locations.

In this study, 14 species were differentiated from each other based on AI (Figure 3B). Of these, five species were analyzed phylogenetically using the intron $\operatorname{tr} n \mathrm{~L}$ sequences. Despite it is a relatively well-conserved sequence, C. gilliesii, C. calycina, C. ferrea, C. echinata, and C. pluviosa were found on well-defined branches (bootstrap $>50 \% ; 10,000$ repetitions; Juchum et al., 2008). C. ferrea, C. gilliessi and C. macrophylum are among the six species with lower values of AI, among the 14 species (Figure 3). Those two species of Caesalpinia s.l are in the same branch of Cenostigma gardneriana in the tree based on molecular data (Manzanilla and Bruneau, 2012). Hence, as proposed by Paszko (2006), it is possible to show the presence of evolutionary differences or congruencies in the morphology of chromosomes and the karyotype asymmetry of Caesalpinia species because AI data were consistent with molecular phylogeny data for these species.

The taxonomic history of Caesalpinia clade revels that is composed of several genera to which Caesalpinia species have been taxonomically assigned (Lewis, 1998). Morphological data on wood anatomy (Gasson et al., 2009) and molecular analysis (Manzanilla and Bruneau, 2012) confirmed the above-mentioned points. Despite the identical chromosome number $(2 \mathrm{n}=24)$ for these species, morphometric chromosome changes based on classical cytogenetics revealed differences between the species and represent an important basis for future studies of molecular cytogenetics in this group.

Most Brazilian Caesalpinia species analyzed in this study showed intermediate asymmetry values and have been proposed for the genus Poincianella (Lewis, 1998; Gasson et al., 2009; Queiroz, 2009; 2010). Despite the limited number of Caesalpinia species whose karyomorphological data were known, chromosomal features can potentially be used as to support the allocation of Caesalpinia in the different genera, at least in the case of Poincianella.

\section{ACKNOWLEDGMENTS}

Thanks to the technician José Lima Paixão for cooperating in the collection and identification of plant material and to Cláusio Antonio Ferreira de Mello for his assistance in the laboratory. Coordenação de Aperfeiçoamento de Pessoal de Nível Superior (CAPES) granted a scholarship to the first author. Conselho Nacional de Desenvolvimento Científico e Tecnológico $(\mathrm{CNPq})$ supported the scientific researcher R.X. Corrêa and provided financial assistance to the project (\#305202/2009-0 and \#473393/2007-7).

\section{REFERENCES}

Alves MAO and Custódio AVC (1989). Cytogenetics of Leguminosae collected in the state of Ceará. Braz. J. Genet. 12: $81-92$.

Atchison E (1951). Studies in the Leguminosae. VI. Chromosome numbers among tropical woody species. Am. J. Bot. 38: $538-546$. 
Auler NMF and Battistin A (1999). Análise do cariótipo de Apuleia leiocarpa (Vog.) Macbr. Cienc. Rural 29: 167-169. Beltrão GTDA and Guerra M (1990). Citogenética de angiospermas coletadas em Pernambuco-III. Cienc. Cult. 42: 839845.

Biondo E, Miotto STS and Schifino-Wittmann MT (2005). Números cromossômicos e implicações sistemáticas em espécies da subfamília Caesalpinioideae (Leguminosae) ocorrentes na região sul do Brasil. Rev. Bras. Bot. 28: 797-808.

Bruneau A, Forest F, Herendeen PS, Klitgaard BB, et al. (2001). Phylogenetic relationships in the Caesalpinioideae (Leguminosae) as inferred from chloroplast trnL intron sequences. Syst. Bot. 26: 487-514.

Bruneau A, Mercure M, Lewis GP and Herendeen PS (2008). Phylogenetic patterns and diversification in the caesalpinioid legumes. Botany 86: 697-718.

Cangiano MA and Bernardello G (2005). Karyotype analysis in Argentinean species of Caesalpinia (Leguminosae). Caryologia 58: 262-268.

Cardoso MA, Provan J, Powell W, Ferreira PCG, et al. (1998). High genetic differentiation among remnant populations of the endangered Caesalpinia echinata Lam. (Leguminosae-Caesalpinioideae). Mol. Ecol. 7: 601-608.

Doyle J, Doyle J, Ballenger J, Dickson E, et al. (1997). A phylogeny of the chloroplast gene $r b c \mathrm{~L}$ in the Leguminosae: taxonomic correlations and insights into the evolution of nodulation. Am. J. Bot. 84: 541.

Doyle JJ, Chappill JA, Bailey DC and Kajita T (2000). Towards a Comprehensive Phylogeny of Legumes: Evidence from $r b c \mathrm{~L}$ Sequences and Non-Molecular Data. In: Advances in Legume Systematics (Herendeen PS and Bruneau A, eds.). Royal Botanic Gardens, Kew, 1-20.

Ferreira DF (2003). Programa Sisvar. Software 5.0. UFLA, Lavras.

Gasson P, Warner K and Lewis GP (2009). Wood anatomy of Caesalpinia s.s., Coulteria, Erythrostemon, Guilandina, Libidibia, Mezoneuron, Poincianella, Pomaria and Tara (Leguminosae, Caesalpinioideae, Caesalpinieae). IAWA J. 30: 247-276.

Goldblatt P (1981). Cytology and the Phylogeny of Leguminosae. In: Advances in Legume Systematics (Polhill RM and Raven PR, eds.). Royal Botanical Gardens, Kew, 427-463.

Guerra M (1990). A situação da citotaxonomia de angiospermas nos trópicos e, em particular, no Brasil. Acta Bot. Bras. 4: 75-86.

Haston EM, Lewis GP and Hawkins JA (2005). A phylogenetic reappraisal of the Peltophorum group (Caesalpinieae: Leguminosae) based on the chloroplast trnL-F, rbcL and rps16 sequence data. Am. J. Bot. 92: 1359-1371.

Herendeen PS (2000). Structural evolution in the Caesalpinioidae (Leguminosae). In: Advances in Legume Systematics (Herendeen PS and Bruneau A, eds.). Royal Botanic Garden, Kew, 45-64.

Huziwara Y (1962). Karyotype analysis in some genera of Compositae. VIII. Further studies on the chromosome of Aster. Am. J. Bot. 49: 116-119.

Jena S, Sahoo P, Mohanty S and Das AB (2004). Identification of RAPD markers, in situ DNA content and structural chromosomal diversity in some legumes of the mangrove flora of Orissa. Genetica 122: 217-226.

Juchum FS, Costa MA, Amorim AM and Corrêa RX (2008). Phylogenetic relationships among morphotypes of Caesalpinia echinata Lam. (Caesalpinioideae: Leguminosae) evidenced by trnL intron sequences. Naturwissenschaften 95: 10851091.

Kajita T, Ohashi H, Tateishi Y, Bailey CD, et al. (2001). RbcL and legume phylogeny, with particular reference to Phaseoleae, Millettieae, and allies. Syst. Bot. 26: 515-536.

Käss E and Wink M (1996). Molecular evolution of the Leguminosae: phylogeny of the three subfamilies based on $r b c \mathrm{~L}-$ sequences. Biochem. Sys. Ecol. 24: 365-378.

Kumari S and Bir SS (1989). Karyomorphological evolution in Caesalpiniaceae. J. Cytol. Genet. 24: 149-163.

Lewis GP (1998). Caesalpinia, a Revision of the Poincianella-Erythrostemon Group. Royal Botanic Gardens, Kew.

Manzanilla V and Bruneau A (2012). Phylogeny reconstruction in the Caesalpinieae grade (Leguminosae) based on duplicated copies of the sucrose synthase gene and plastid markers. Mol. Phylogenet. Evol. 65: 149-162.

Melo SCO, Gaiotto FA, Cupertino FB, Corrêa RX, et al. (2007). Microsatellite markers for Caesalpinia echinata Lam. (Brazilwood), a tree that named a country. Conserv. Genet. 8: 1269-1271.

Paszko B (2006). A critical review and a new proposal of karyotype asymmetry indices. Plant Syst. Evol. 258: 39-48.

Peruzzi L, Leitch IJ and Caparelli KF (2009). Chromosome diversity and evolution in Liliaceae. Ann. Bot. 103: 459-475.

Pierozzi NI, Borghi TC and Silvarolla MB (2012). A karyological study in some species of Coffea L. and in the closest relative Psilanthus travancorensis (Wight \& Arn.) J.-F. Leroy. Not. Bot. Hort. Agrobo. 40: 39-45.

Queiroz LP (2009). Leguminosas da Caatinga. UEFS, Feira de Santana.

Queiroz LP (2010). New combinations in Libidibia (DC.) Schltdl. and Poincianella britton and rose (Leguminosae, Caesalpinioideae). Neodiversity 5: 11-12.

Rocha YT (2004). Ibirapitanga: História, Distribuição Geográfica e Conservação do Pau-Brasil (Caesalpinia echinata Lam., Leguminosae) do Descobrimento à Atualidade. Doctoral thesis. Universidade de São Paulo, São Paulo. 
Rodrigues PS, Souza MM and Corrêa RX (2012). Karyomorphology of Caesalpinia species (Caesalpinioideae: Fabaceae) from Caatinga and Mata Atlântica biomes of Brazil. J. Plant Stud. 1: 82-91.

Romero Zarco C (1986). A new method for estimating karyotype asymmetry. Taxon 35: 526-530.

Rondon JN, Zaidan LBP, Domingos M and Barbedo CJ (2006). Vegetative responses to temperature and photoperiod in saplings of brazilwood (Caesalpinia echinata Lam., Leguminosae). Braz. J. Plant Physiol. 18: 467-474.

Souza MGC and Benko-Iseppon AM (2004). Cytogenetics and chromosome banding patterns in Caesalpinioideae and Papilionioideae species of Pará, Amazonas, Brazil. Bot. J. Linn. Soc. 144: 181-191.

Stebbins GL (1971). Chromosomal Evolution in Higher Plants. Edward Arnold Ltd., London.

Tucker SC and Douglas AW (1994). Ontogenetic Evidence and Phylogenetic Relationships Among Basal Taxa of Legumes. In: Advances in Legume Systematics (Ferguson IK and Tucker SC, eds.). Royal Botanic Gardens, Kew, 11-32.

Varty N (1998). Caesalpinia echinata. In: IUCN 2012. IUCN Red List of Threatened Species. Available at [http://www. iucnredlist.org]. Accessed January 17, 2013.

Warwick MC and Lewis GP (2009). A revision of Cenostigma (Leguminosae - Caesalpinioideae - Caesalpinieae), a genus endemic to Brazil. Kew Bull. 64: 135-146. 